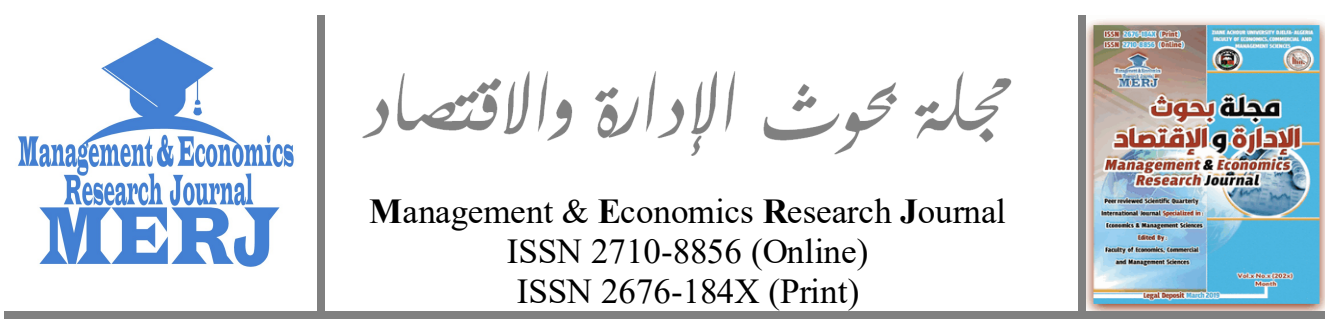

Management \& Economics Research Journal, Vol. 2 No.4 (2020), pp. 1-9

do) https://doi.org/10.48100/merj.v2i4.121

\title{
Mind the Gap of Inequalities Between and Within Countries
}

\author{
Alexandru Trifu ${ }^{1}$ (i) \\ ${ }^{1}$ Professor Ph.D, University "Petre Andrei” of Iasi (Romania) \\ $\triangle$ trifu.alex@gmail.com
}

\author{
Received: 15-06-2020 \\ Accepted: 22-08-2020 \\ Published: 22-09-2020
}

\begin{abstract}
:
"Mind the gap!" is an expression meaning a visual or audible warning phrase to take caution while crossing the gap between the train door and the platform. The subject of this paper is to highlight the existing inequalities, even in the case of East-West, and the necessity that, by political will and concrete economic and social measures, not only by warnings, mitigate these disparities for the benefit of the parties concerned. This means that, through continuous political awareness of these inequalities, paying attention to this scourge of today's world and implementing such measures to ensure a strategic game-type win-win. The methods used in this paper are represented by primary data collected from international reports and situations about the status of today's world countries and national analyses published. All these data and information become base for the analyses of this issue and the emergence of valuable recommendations, rather than conclusions, regarding the counterbalance between East and West, apart from the famous and classic example of David Ricardo regarding the theory of the international trade between the rich and developed North and the poor and underdeveloped/developing South, in Europe and the world. Awareness, alertness, prompt responses to all challenges and a balanced development type win-win are the keys to a modus vivendi and sustainable evolution.
\end{abstract}

Keywords: Inequality, Development, Workforce Migration, Win-Win Game.

JEL Codes: F16, F63, O15.

•Corresponding author: Univ. "Petre Andrei” of Iasi, Roumanie.

[凹trifu.alex@gmail.com] 


\section{Introduction}

A simple background on this topic: what is economic inequality? It refers to an unequal distribution of income and opportunities between people in society, regions, and countries. To overcome Jean-Jacques Rousseau's opinion that people are born equal and the idea that if people are born in poverty, that automatically means staying poor forever.

Nowadays, in the IT \& $\mathrm{C}$ revolution era and with a higher level of understanding about what is happening, we think that by education, training policies, enhancing skills, and political will, it is possible to change the situation within a country or between countries in their relationships. Some authors (Peterson, 2017) consider that poverty and economic inequalities, in general, represent a disease of modern society. There are necessary policies and measures, especially from the most developed countries and international organizations, to be implemented to reduce inequalities and ensure that the respective country or group of countries "swim," not "sink." Some measures available to governments are represented by tax and spending tools, along with progressive taxation and welfare transfers.

Analyzing the data and the realities of the last decades, we can affirm that it can be large prosperity with lower economic inequalities. Attitudes towards tackling inequalities also depend on the people's view of work and how it is valued.

\section{Inequalities, as a major problem of today}

For the present analysis, we use the Report of the Stiglitz-SenFitoussi Commission (2009) predominantly to understand the main features of this issue. All discussion is around the income, especially household income, that has been adjusted for publicly in-kind transfers, such as public spending on education and health (in fact, part of the larger concept of "Human Capital"). How many people benefit from basic needs (from the Maslow Pyramid of Needs) such as food, water, clothes, homes, and security? The more convenient the working conditions are, the higher the productivity will be and the people happier. 


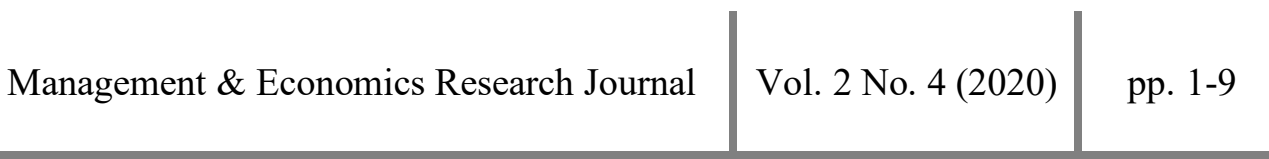

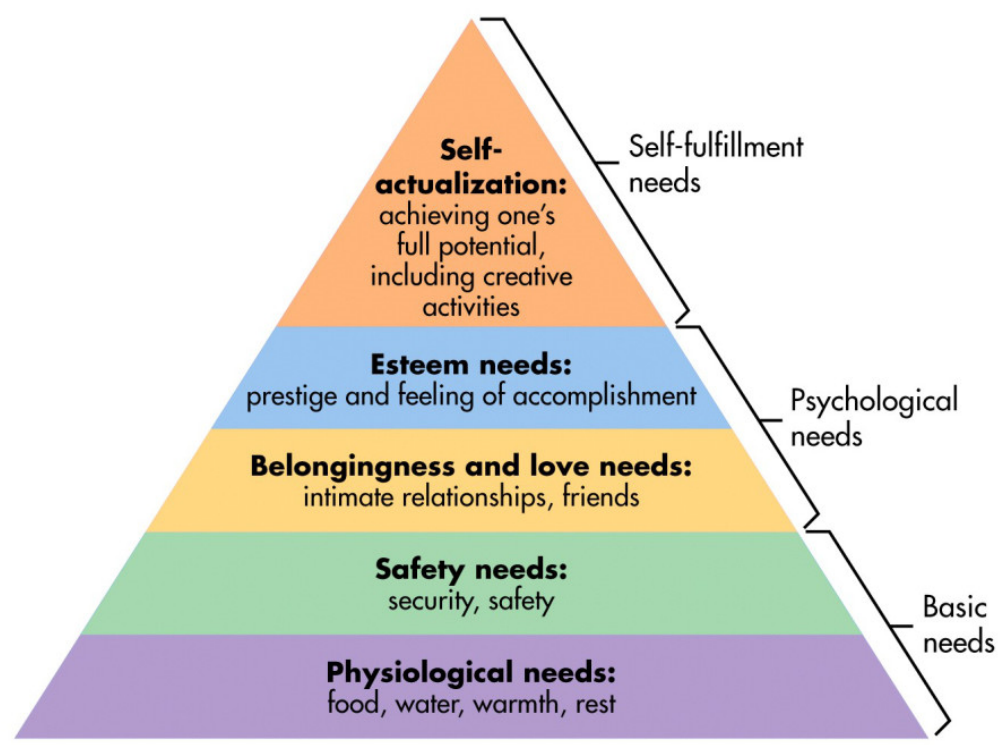

Figure 1. Maslow's Hierarchy of Needs

Source: (McLeod, S., 2020)

Analyzing the data from OECD reports $(2012,2019)$, we can see some situations illustrating the existence of inequalities around the world. Thus, it is a figure in the report 2012 pp 189, presenting Country groups with similar patterns of inequality:

- Denmark, Iceland, Norway, Sweden, and Switzerland-high employment rates, little wage dispersion, and taxes are not highly progressive;

- Belgium, Czech Republic, Estonia, Finland, France, Italy, Slovakia, and Slovenia-little wage variation, low employment or high parttime rate, highly concentrated capital and self-employment income;

- Austria, Germany, Greece, Hungary, Japan, Korea, Luxemburg, and Poland, Spain-individual labor income is concentrated (above average dispersion in wages and low employment);

- Australia, Canada, Ireland, Netherlands, New Zealand, and United Kingdom-above average dispersion in wage, coupled with a high part-time rate;

- Chile, Israel, Mexico, Portugal, Turkey, United States-high concentration of labor, capital, and self-employment income, plus a high poverty rate.

From a. to e., it ranges from low inequality in household income to high inequality in household income, the primary indicator in the analysis. However, the 2019 Report is a more specific and qualitative approach 
because a subchapter analyzes the equality opportunities ( $p p$ 41). More precisely, it is about structural reforms (qualitative ones) to promote growth and equality opportunities. The OECD Report advocates many priorities likely to increase equal opportunities for workers, the main force of production, in any economy. Such priorities aim to provide adequate and improved skills, the internal environment quality, and possibilities to improve the income mobility of workers. People. The main scope is to reduce income inequalities between advanced and emerging-market countries. It was observed that the gaps have narrowed. Even in domains such as education, infrastructure, and labor market regulation, the emerging countries were at better values than the total 2019 priorities.

Another significant analysis for this paper is that one of the inequalities in the Middle East is considered the unequal region of the world and their importance for the entire world's existence (Assouad, 2020). In synthesis, it is considered that the extreme inequality in this region is due to the huge income differences between oil-rich and population-rich countries. Thus, the Gulf States represented only $15 \$$ of the region's total population in 2016 but received almost half of the total region's income (somehow about the Pareto's Principle 20/80). I.e., a major gap between countries with enormous revenues from hydrocarbons and the other Arab countries. Also, Assouad's analysis reveals that the sole reliable inequality data from the region in Lebanon and some several countries, such as Algeria, Egypt, Iraq, and Lebanon, are rentier states, meaning the income derived from "the gift of nature" (Beblawi, 1987).

However, this favorable trend was suddenly interrupted by the challenge and the spread out of COVID-19. As a consequence, OECD unveiled the economic outlook for 2020, with a global contraction of at least $6 \%$ if the pandemic remains under the control of people and authorities. Amongst OECD countries, the most brutal hit will be Spain, France, Italy, and the UK, precisely the most affected European countries by COVID-19. The recovery process is considered under a U-shape rather than V-shape (McCaffrey, June 2020).

This situation briefly reminds us of David Ricardo's theory of international trade, issued in 1817 (Bauer, 2007). Thus, Ricardo suggested that countries specialized in the production of the commodities in which they have a comparative advantage are more capable of achieving higher standards of consumption and living, and more revenues, by trading these goods with other countries. Also, in the spirit of the present analysis, it is necessary to highlight the example of China vs. the USA. Although the Chinese average labor productivity is only a fraction of the American one, 
as we know and see, China exports plenty of goods to the United States and has a comparative advantage in producing labor-intensive products, such as textiles, toys, phones, and communications devices, and other equipment. The recent improvements, especially regarding the structural changes in the Chinese workforce and its comparative advantage, we can find in the works of different authors, such as Jun Hou, Stephen Gelb, Linda Calabrese (2017), and Emmanuel Olusegun Stober (2014).

\section{Methodology}

We used primary data regarding the issue in discussion from international institutions' reports, such as OECD, UN, and European Union, and national organizations. This aspect, along with the overview of opinions, ideas, and forecasts in this respect, allows us to target a conclusion referring to the necessity, as much as possible, to mitigate the disparities/gaps between states and to ensure a reasonable economic game type win-win.

\section{Exposure of the realities}

Our analysis starts with the basic example of Germany, reunified on October 1st, 1990, by gathering in a single unit of former Eastern Germany (the German Democratic Republic, a Communist country) and the Federal Republic of Germany, one of the six constitutive pillars of the European Economic Market in 1957 at Rome. Still, the inequalities persist.

We can say that this is a classic example of the economic inequalities between East and West and partial success in balancing these inequalities, of course, in this example of a reunited Germany (1990). Even though the former German Democratic Republic (DDR) was a leading economic country amongst countries forming the Socialist system before 1990 , it was. Still, it is not easy to ring the level of development and, implicitly, of living, from Eastern Germany to that of West Germany (called the Federal Republic of Germany). Billions of euros were injected into former East Germany. Even it was considered a bit of a trillion euros from West Germany to keep the entire German nation (Blau, 2010) afloat. However, a large amount of money went to the wrong projects, and more was spent on social programs. As a consequence, it is considered a loss for the German economy.

This is considered an eloquent example in this respect because, in the case of Europe, we can talk about the entire Central and Eastern countries (former Socialist countries) joining the unique and original 
economic and political construction of the European Union, BUT with a severe handicap regarding economic, social and democracy aspects. Why do the latest discussions within the EU remind us of a Europe with two or more speeds? Exactly, because the majority of Member States from Central and Eastern Europe are left behind, a significant effort is needed, not only financial, to bring these countries to a competitive level with the West. No national or regional economy (such European Union) can work with disparities between countries or regions of a country. It is like a construction erected with pillars of different heights, but especially from different structures, leading to an unstable and non-functional construction.

No matter the geographic position, BUT taking into account the developing level. In this challenging period of the pandemic with COVID19, international organizations and structures, such as the United Nations and the European Commission, thought and put into practice economic and social schemes and packages in order to help/support the most vulnerable countries, or parts of countries, which need these funds most.

For example, Antonio, Guterres-United Nations Secretary-General, has launched a \$2 billion global response to support the efforts to combat the COVID-19 pandemic. Even the funding appeals totalize $\$ 5$ billion from aid groups. Nevertheless, as the logo of this paper says: "Mind the gap of inequalities!"

On the other side, the European Commission recently laid out the post-pandemic supportive plan of about 1.85 trillion euros based on the long-term EU budget and special recovery fund. At the same, we have to understand that grants and the other one by loans with reduced interest represent a part of this amount. More precisely, the recovery fund approved at the end of May is around 750 billion euros, from which 500 billion are grants and the rest are loans (Gill \& McCaffrey, 2020).

In this overview of the inequality issue, we must not forget a turning point represented by the G8 Summit in Scotland in 2005. Why? Because after this meeting, it was going to write off the entire $\$ 40$ billion debt owed by 18 highly indebted developing countries to the World Bank, IMF, and African Development Fund, and, at the same time, it was to be granted substantial aid especially for Africa countries, i.e., to underdeveloped and developing countries, in order to mitigate the inequalities between countries. However, no political will was manifested, as in many other critical moments of the recent era. The continuation of structural adjustments exceeded the benefits of debt cancellation and aid-increasing measures. As a consequence, this project has failed. 
Another recent example regards the convergence criteria of all EU Member States to join the Eurozone as soon as possible. A few days ago, a report was issued, and the conclusions are unfavorable for some countries, especially Romania (Convergence Reports, June 2020). The economicsocial disparities between the eight development regions and, as a whole, one of the reduced levels of development among the 27 EU-Member States lead to the reality that Romania does not meet any of the 4 (four) criteria of convergence to the Eurozone.

Within the connections between East-West, we can present one of the winners in this pandemic period: a company from Malaysia, Top Glove. This is a major producer/manufacturer of personal protective equipment, with huge earnings due to the increased demands (higher than the offer) during the pandemic. Accordingly, to the data presented, the profit after tax increased to $365 \%$ at the end of May (McCaffrey, 2020). Moreover, the situation is valid for countries from the same area, such as Singapore, China, and Korea, which were prepared to send masks and other instruments and devices promptly for the fight against COVID-19.

Last but not least, it is a problem of Foreign Direct Investments (FDI) from developed countries to emerging/developing countries with the awareness that the essence of FDIs is not the capital per se, but technologies and other tangible assets, for capitalization of the human, material and financial resources of the evolving states (see India's example in Chalapati Rao, Dhar, 2018).

The main feature of the income inequalities between East and West (even within Europe) is represented by the migration of the workforce, mainly medium and high specialized from countries of Asia to Europe, from Eastern Europe to Western countries, including from Europe to the US. Moreover, conforming to the law of communicating vessels, staff and workers shortage is covered with workers and specialists from Eastern and Southern countries.

It is an apparent move to places better paid and with a decent and high standard of living. A great example is Romania, probably "the first exporter of doctors" in the world, i.e., already trained specialists put at work in other countries.

\section{Conclusion}

This captures that the inequalities/gaps between East and West are less noticeable and discussed than those between North and South. We already saw examples presenting the double-way relationships between the East (that is, Asia) and the West. These structural/commercial connections 
are relevant for reducing disparities between East and West. However, the financial support/aid must be combined with the quality and productivity of work, including the knowledge and the skills of the workforce from the fewer countries or regions involved in these connections. Also, along with political will, drastic structural (qualitative) reforms are needed targeting poverty and inequality amongst regions and countries, and support of international/regional organizations for every wheel of the world's functioning economy is needed.

We are passing through a very tough and challenging period of our lives. We think that the awareness of what is going on and its repercussions, alertness, and prompt responses to all challenges, along with attention to the existing disparities, should not deepen. Here they are the main keys for this specific period and even in the medium run.

However, because it is about people/workers and their economic and social status, everything depends on the political will, in order to issue regulations, norms, and laws to ensure reasonable equity within societies and economies and between countries, in a manner of win-win game, but far from being equal for all parts involved in.

\section{References}

Assouad, L. (2020). Inequality and Its Discontents in the Middle East, Retrieved from www.carnegie-mec.org/2020/ accessed May 30, 2020.

Bauer, M. (2007). The importance of the Ricardian theory of international trade, Retrieved from www.grin.com/document/ accessed May 25, 2020.

Beblawi, H. (1987). The Rentier State in the Arab World, published by Pluto Journals, Retrieved from www.jstor.org/stable/ accessed June 1 st, 2020.

Blau, John. (2020). Eastern Germany is Western Germany's trillion euro bet, Retrieved from www.dw.com/en/ accessed May 27, 2020.

Chalapati Rao, K. S., \& Biswajit, D. (2018). India Recent Inward Foreign Direct Investment, New Delhi: Institute for Studies in Industrial Development.

Gill, J., \& McCaffrey D. (2020). EU announces financial "firepower" of 1.85 trillion with 750 billion for COVID recovery, Retrieved from www.euronews.com May 25, accessed June 1st, 2020.

Jun H., Sterphen G., \& Linda C. (2017). The shift in manufacturing employment in China, Background paper, Supporting Economic Transformation, August 2017. 
McCaffrey, D. (May-June 2020). Coronavirus briefings, months of May and June, Retrieved from www.euronews.com accessed June 11-13, 2020.

Stober, E. O. (2014). The influence of labour intensive export on China's economy growth, CCREI Working papers, Bucharest University of Economic Studies, April 2014.

McLeod, S. (2020). Maslow's Hierarchy of Needs, Retrieved from www.simplypsychology.org accessed May 30, 2020.

Peterson, E. W. F. (2017) Is Economic Inequality Really A Problem? A Review of the Arguments, Retrieved from www.repec.ideas.org, accessed May 25, 2020.

Convergence Reports. (June 10, 2020). Retrieved from www.ec.europa.eu/info/ accessed June 11, 2020.

Finding the fight against COVID-19 in the world's poorest countries (March 20, 2020), Retrieved from www.un.org/en/ accessed May 28, 2020.

Going for Growth 2019: The time for reform is now, Retrieved from www.oecd.org/economy/ accessed June 6, 2020.

Reducing income inequality while boosting economic growth: Can it be done? Going for Growth 2012, part II, chapter 5, Retrieved from www.oecd.org/economy/ accessed June 3, 2020.

(C) 2020 the Author(s). This is an open access article distributed under the terms of Creative Commons Attribution-Non Commercial License (CC BY-NC 4.0) which permits use, distribution and reproduction in any medium, provided the original work is properly cited and is not used for commercial purposes.

\section{Recommended citation:}

Trifu, A. (2020). Mind the Gap of Inequalities Between and Within Countries. Management \& Economics Research Journal, 2(4), 1-9. https://mer-j.com/merj/index.php/merj/article/view/121 